\title{
É legal? A regulação da Comunicação Comunitária na esquerda latino-americana
}

\author{
Gislene Moreira*
}

\section{Resumo}

A América Latina iniciou o novo milênio com inovações nas políticas do setor da Comunicação, retomando o debate sobre as leis de meios. Esse processo acompanhou os giros democráticos no continente nos anos 2000. Mas que avanços normativos as novas esquerdas latino-americanas aportaram aos meios comunitários? Com o objetivo de compreender a relação entre governos progressistas e regulação da mídia comunitária, este estudo analisou as disputas normativas na Argentina, Brasil e Venezuela na última década com base em estudo de documentos, entrevistas etc. Foram comparadas as leis, a partir da visão dos atores envolvidos no debate. $\mathrm{O}$ resultado indica que a adoção de regras mais progressistas no setor não representa uma opção prioritária das novas esquerdas pelo tema. As novas leis são produto de uma complexa correlação de forças, em que a agência dos atores contra-hegemônicos é decisiva para a construção de novos caminhos.

Palavras chave: Comunicação Comunitária. Legislação. Políticas Públicas de Comunicação. América Latina.

\section{It's legal? The regulation for the Comunity Communication in the latin american's left}

\section{Abstract}

The new millennium in Latin America began with innovation in the policies of Communication recovering the debate about media laws. This process followed

\footnotetext{
* Professora do Curso de Jornalismo Multimeios no Departamento de Ciências Humanas III da UNEB, Juazeiro-BA, Brasil. Doutora em Ciências Sociais pela Flacso-México e mestre em Cultura e Sociedade pela UFBA. Dedica-se a temas de movimentos sociais, eduComunicação, mídia comunitária e políticas de Comunicação no Sertão brasileiro e na Comunicação na América Latina.

E-mail:ggomes@uneb.br
} 
the democratic revolutions on the continent in the 2000s. But what normative advances the new left governments brought to the Media Community? With the goal to understand the relationship between progressive governments and regulation of Community Media, this study analyzed the normative disputes in Argentina, Brazil and Venezuela in the past decade based on studies of documents, interviews etc. We compared the laws, from the perspective of the actors involved in the subject. The result indicates that the adoption of rules most progressive in the industry is not a priority option of the left parties involved in the theme. The new laws are the result of a complex balance of forces, in that the participation of counter-hegemonic actors is crucial to building new ways. Keywords: Comunity Communication. Law. Communication's Public Politic. Latin America.

\section{És legal? La regulación de la comunicación comunitaria en la izquierda latino-americana}

\section{Resumen}

América Latina ha comenzado el nuevo milenio con innovaciones políticas en el sector de la Comunicación, com el retorno los debates sobre las leyes de Medios de Comunicación. Este proceso siguió las revoluciones democráticas en el continente en la década de 2000. ¿Pero que avances normativos la nueva izquierda latinoamericana traje a la comunicación comunitaria? Para entender la relación entre los gobiernos progresistas y la regulación de los Medios Comunitarios, este estudio analiza las diferencias normativas en Argentina, Brasil y Venezuela en los últimos diez años a partir del estudio de documentos, entrevistas etc. Se compararon las leyes, desde la perspectiva de los actores involucrados en el debate. El resultado indica que la adopción de normas más avanzadas no es una opción prioritaria a la nueva izquierda para el tema. Las nuevas leyes son el producto de un complejo equilibrio de fuerzas, la quales la actuacíon de los actores contra-hegemónicos es crucial para la construcción de nuevas propuestas. Palabras clave: Comunicación Comunitaria. Legislación. Políticas Públicas de la Comunicación. América Latina.

\section{Introdução}
1
s regras da radiodifusão na América Latina foram fixadas no século 20 por meio de perigosas relações de poder en- tre elites políticas e empresários midiáticos (FOX, 1997). A exploração não comercial do espectro foi ignorada, coibida e proibida em todos os marcos normativos do continente até o fi- nal dos anos 90 (MOREIRA, 2011). Sustentados nestas práticas, 
emergiram os principais conglomerados midiáticos do continente. Os grupos Clarín, na Argentina, Globo, no Brasil, e Cisneros, na Venezuela foram alguns dos principais beneficiários destas regras, se constituindo como as grandes potências do setor (MASTRINI e BECERRA, 2009; MORAES, 2009).

Apesar das práticas de repressão, extermínio, criminalização e criação de barreiras legais e econômicas, durante décadas, milhares de meios comunitários, alternativos e livres atuaram clandestinamente $^{1}$ (GUMUCIO-DRAGON e TUFTE, 2006); e o tema das rádios comunitárias se constituiu como a principal demanda nas lutas por "outra Comunicação" (AMARC, 2010; PERUZZO, 2010).

Com as viradas democráticas ${ }^{2}$ que sacudiram a América Latina nos anos 2000 se alimentaram as expectativas de mudanças nesta estrutura e de abertura de brechas para os meios comunitários. Era possível aos governos Kirchner, Lula e Chávez alterar as regras do jogo? Esta demanda fazia parte de seus projetos políticos? Que resultados normativos esses governos proporcionaram? Para responder a estas questões, este estudo escolheu Argentina, Brasil e Venezuela como casos paradigmáticos dos embates midiáticos na região ${ }^{3}$.

Fruto da tese doutoral As Formigas de Macondo: Contrahegemonia e políticas de Comunicação Comunitária na América Latina

\footnotetext{
${ }^{1}$ A história dos meios alternativos na América Latina remonta à década de 1920, com a imprensa operária. Nos anos 30, surgiram as rádios mineiras na Bolívia. Nos anos 70, o continente provocou o debate da Nova Ordem Mundial da Informação e Comunicação (NOMIC), e nos 80/90 ocorreu um "boom" de experiências de Comunicação popular mesmo sem nenhum amparo legal.

${ }^{2}$ As mudanças políticas na Argentina, Brasil, Bolívia, Chile, Equador, Honduras, Nicarágua, Paraguai, Uruguai e Venezuela, entre outros, foram apontadas como respostas ao neoliberalismo e ao conservadorismo político (Plot e Semán, 2007) e foram chamados de giros à esquerda na literatura da Ciência Política (Natanson, 2008).

${ }^{3}$ No cenário macro-político, os venezuelanos realizaram rupturas institucionais bruscas. O Brasil optou por uma transição conservadora e a Argentina construiu um desenho misto que preservou as instituições tradicionais, mas sinalizou para mecanismos econômicos e políticos alternativos (Natanson, 2008).

${ }^{4}$ Defendida em 2011, a tese conquistou menção honrosa como um dos melhores trabalhos do continente no I Concurso de Teses sobre o Brasil e a América Latina realizado pela Flacso, ALAS e Clacso em 2012. Na premiação, foi a única pesquisa destacada na área da Comunicação entre os mais de 100 inscritos.
} 
este artigo apresenta uma comparação entre as normas de mídia comunitária e os cenários políticos de ação coletiva da Coalizão para uma Radiodifusão Democrática Argentina, da Comissão Pró-Conferência, no Brasil, e as articulações da Associação Nacional de Meios Comunitários Livres e Alternativos (ANMCLA), na Venezuela.

Para construir esta análise, foi realizado trabalho de campo e estâncias de investigação ${ }^{5}$ nos três países. A pesquisa foi realizada entre 2008 e 2011 e incluiu revisão documental e bibliográfica, 40 entrevistas semi-estruturadas, e seis grupos focais junto a líderes dos movimentos, gestores públicos e especialistas no tema. Também constou de observação participante em oito atividades internas de cinco movimentos relevantes no setor, 15 visitas a emissoras comunitárias envolvidas nas novas leis, e participação em seis eventos e congressos sobre o tema na Argentina e Venezuela. Além disso, desde 2002 a pesquisadora participa ativamente dos debates em torno ao tema no Brasil, tendo integrado o Grupo de Trabalho Pró-Conferência entre 2006 e 2008 que realizou a I Conferência de Comunicação na Bahia.

O marco interpretativo mesclou aportes da Economia Política da Comunicação, Política Comparada, e Etnografia ${ }^{6}$ para dar ênfase à perspectiva dos atores subalternos no jogo regulatório. A partir da correlação entre os resultados normativos e os depoimentos dos envolvidos, o estudo esperava indicar o nível de envolvimento das novas esquerdas com o tema da mídia comunitária.

\footnotetext{
${ }^{5} \mathrm{Na}$ Argentina, a estância foi acompanhada pelo Dr. Martín Becerra da Universidade de Quilmes. No Brasil, contou com a orientação do Dr. Valério Cruz Brittos, da Unisinos. Na Venezuela, os doutores Orlando Villa-lobos e Jesús Urbina, da Universidad de Zulia, e Jesús María Aguirre, da Universidade Católica, foram apoiadores do estudo.

${ }^{6}$ A etnografia é uma perspectiva metodológica das Ciências Sociais que busca incorporar a perspectiva dos atores na própria construção e interpretação do problema de pesquisa. Privilegia mecanismos de coleta mais qualitativos, como observação participante, realização de entrevistas etc. São autores de referência nomes como Garfinkel e Goffman.
} 


\section{Contextos das lutas por novas políticas de Comunicação}

\section{Argentina}

Na Argentina assumida por Nestor Kirchner, em 2003, exatamente 20 anos após a redemocratização do país, ainda prevalecia a Lei de Radiodifusão $22.285 / 80^{7}$ aprovada na ditadura militar de Videla ${ }^{8}$. O marco ignorava e eliminava a possibilidade de exploração não comercial do espectro (MASTRINI, 2009; SEL, 2010).

Neste contexto, foi criada, em 2004, a Coalizão para uma Radiodifusão Democrática (CRD), uma articulação que reuniu mais de 800 entidades de direitos humanos, meios comunitários de diversas correntes, centrais sindicais, universidades, artistas, militantes etc. Entre eles, se destacou a ação do Fórum Argentino de Rádios Comunitárias (FARCO) como entidade articuladora (SEL, 2010). A entidade já existia desde 1985, mas até então era um grupo frágil e sem muita projeção política.

Organizados coletivamente, esses atores conquistaram a Lei 26.053/05, por meio da incidência junto à Suprema Corte de Justiça, que reconheceu o direito de exploração não-comercial do espectro. Mas o cenário político era ambíguo. O governo de Kirchner confrontava discursivamente com os meios massivos, mas de outro lado não favorecia a pauta alternativa. Depois, surpreendeu o movimento com o chamado "golpe das licenças", que por meio do Decreto 527/05 prorrogou o tempo das concessões dos conglomerados privados sem enfrentar o debate público (MASTRINI, 2009).

O episódio quase provocou a ruptura da Coalizão que, para evitar a divisão entre favoráveis e contrários a seguir negociando com o

\footnotetext{
${ }^{7}$ A medida é considerada por analistas como um marco que favoreceu ao grupo privado Clarín, e que legitimou a eliminação das vozes antagônicas. A medida proibia o uso do espectro radioelétrico para fins não comerciais. Nos anos de redemocratização do país, continuou vigente, mas foi alterada sucessivamente por decretos que permitiram o avanço da política neoliberal no setor (Mastrini, 2009). ${ }^{8}$ O governo militar argentino foi considerado um dos mais duros episódios na repressão aos direitos humanos na história do continente. A gestão de Videla (1976-1981) representa o momento mais crítico, o que evidencia o caráter autoritário da normativa em radiodifusão.
} 
governo, construiu uma base de consenso chamada de os 21 Pontos para uma Nova Lei de Meios da Democracia. Nenhuma entidade que fizesse parte da Coalizão poderia negociar individualmente com o governo sem tomar TODOS esses pontos como agenda básica. Entre eles, estava a demanda de 33\% do espectro para a exploração sem fins lucrativos, incluindo os meios comunitários.

A pauta da CDR ganhou fôlego com a eleição de Cristina Kirchner (2008). No mesmo ano, a presidenta rompeu a tradicional aliança com a mídia comercial, em especial com o jornal Clarín, durante o conflito do campo ${ }^{9}$. Até então, se dizia que nenhum governo sobrevivia a três capas contrárias no jornal. Cristina sobreviveu a várias, e passou a buscar aliados.

Foi assim que, em 2009, a Coalizão se aproximou da presidenta. Buscando legitimidade pública para enfrentar o maior grupo de Comunicação do país, Cristina adotou os 21 Pontos como base do anteprojeto governista na maior consulta legislativa já realizada na Argentina ${ }^{10}$. E os atores da CDR, com seus assessores jurídicos, pesquisadores acadêmicos e militantes foram a principal base de apoio. A aliança Coalizão-Presidência se concretizou com a aprovação da famosa Lei de Meios (Lei de Serviços Audiovisuais 26.522/09), e seguiu nas batalhas judiciais para garantir a constitucionalidade da normativa, pois depois da aprovação no Congresso, várias medidas judiciais impediram a implantação legal da nova lei.

\footnotetext{
${ }^{9}$ Em 2008, a presidenta Cristina Kirchner instaurou novas regras tributárias restritivas à exportação de produtos primários, como a soja. A medida confrontou os interesses dos produtores agropecuários, que iniciaram um conflito que quase derrubou o governo (Sel, 2010).

${ }^{10}$ A tradição legislativa Argentina não conta de muitos mecanismos de participação. Mas no caso do ante-projeto da "Nova Lei de Meios", a presidenta implantou um mecanismo inédito de consultas públicas, que realizou 28 Fóruns durante cinco meses e passou por todas as províncias do país. Depois, na Câmara de Deputados, o projeto incorporou ainda mais mecanismos de debates, citando os autores das propostas no projeto, e redigindo o texto com notas de direito comparado, com base nos estándares de direitos humanos e das Relatorias de Liberdade de Expressão. Tudo isso, para blindar publicamente a lei contra os evidentes ataques conservadores. Em todas essas etapas, a Coalizão foi fundamental para garantir a mobilização e qualidade dos debates.
} 


\section{Brasil}

Na posse de Lula, os brasileiros eram regulados pelo Código Brasileiro de Telecomunicações (CBT - Lei 4.117 de 1962), e o país contava com uma Lei de Radiodifusão Comunitária (9.612/98), que reconhecia o serviço, mas reduzia a exploração do espectro a limites geográficos e burocráticos bastante restritivos (ROLIM, 2008; PERUZZO, 2010) ${ }^{11}$.

O movimento de Comunicação Comunitária no país se iniciou no final dos anos 80 , com o processo de redemocratização. $\mathrm{Na}$ década de 90 , se destacou a ação da Frente Nacional pela Democratização da Comunicação (FNDC), que reunia entidades como a Federação Nacional de Jornalistas (FENAJ), a Executiva Nacional dos Estudantes de Comunicação (ENECOS) e a Associação Brasileira de Radiodifusão Comunitária (ABRAÇO). Em uma década, esses atores participaram dos debates do Capítulo $\mathrm{V}$ da Constituição de 1988, das batalhas pela regulação do Conselho de Comunicação no início dos anos 90, e da "Guerra do Cabo" - que se iniciou em 1992 e culminou com a conquista da Lei do Cabo em 1995. Em 1998, foi a vez da aprovação da polêmica Lei de Radiodifusão Comunitária e, em 2001, veio o Código Brasileiro de Telecomunicações.

Nesta maratona, foram poucas as conquistas. A frustração legislativa e o aumento da repressão, somados a uma fragmentação ideológica, contribuíram para que o movimento no setor avançasse disperso, na clandestinidade e com finalidades bastante díspares. A ABRAÇO, em sua pretensão de representar o coletivo, nunca conseguiu reunir nem 10\% das 20 mil emissoras estimadas, e vá-

${ }^{11}$ Nos anos 90 houve um boom de rádios comunitárias no país, e ao final da década eram estimadas em mais de 20 mil, transformando o tema num problema político emergente. A ausência normativa para a questão abriu precedente para que várias emissoras conquistassem autorizações na justiça. Em 1996, foram apresentados sete projetos de lei para regular a questão. No debate, ficou evidente a diferença entre o projeto que pretendia reconhecer e promover a transmissão comunitária e o que se dirigia a conter o movimento e reafirmar o monopólio privado. A Lei aprovada tentou vagamente conciliar os dois extremos, e se por um lado reconhece o serviço, de outro adota critérios bastante restritivos (Moraes, 2009; Peruzzo, 2010; Rolim, 2008). 
rias entidades passaram a disputar o posto de líder do movimento (PERUZZO, 2010).

Refletindo a fragmentação, a gestão de Luíz Inácio Lula da Silva (2003-2010) diluiu a política de Comunicação em várias frentes $^{12}$ e as entidades do setor atuaram de maneira isolada e coorporativa (MOREIRA, 2011).

Só sobre rádios comunitárias, a ABRAÇO participou de dois grupos de trabalho (2003 e 2005), enquanto a FENAJ tentava aprovar o Conselho de Jornalistas em uma incidência isolada junto à Casa Civil. Vários outros canais paralelos de negociação foram apresentados pelos entrevistados, revelando uma profunda dispersão das pautas e espaços de luta. Estes atores afirmam que o sentimento era ambíguo, uma vez que, se por um lado se sentiam mais reconhecidos, por outro estavam frustrados pela falta de conquistas efetivas.

Esta contradição não foi exclusiva ao setor da Comunicação, e se expandiu a importantes agendas dos movimentos sociais do país, contribuindo para uma desmobilização generalizada. As distintas respostas políticas do governo e a aposta em mecanismos bastante frágeis de participação levaram os movimentos da "euforia" e ilusão de poder para a resignação a uma política de sustentação do projeto neoliberal (BOITO JR, 2010).

$\mathrm{Na}$ área da Comunicação, Lula evitava e temia a confrontação direta com os grandes meios, acumulando vários episódios frustrados ${ }^{13}$. Em sua gestão, houve um considerável aumento da

\footnotetext{
${ }^{12} \mathrm{O}$ Governo adotou uma engenharia da política de Comunicação em que além do Ministério das Comunicações, a Secretaria de Comunicação da Presidência, o Ministério da Cultura, o Ministério da Ciência e Tecnologia e até a Secretaria de Direitos Humanos intervieram no tema de maneira desarticulada, fragmentada e muitas vezes com posturas contraditórias, revelando o esfacelamento da questão dentro da gestão lulista.

${ }^{13}$ A expectativa dos movimentos era que Lula criasse uma Lei Geral da Comunicação de Massas. Mas todos os poucos sinais que sua gestão deu neste sentido foram abortadas depois das enfáticas reações dos grandes conglomerados. Isto se reflete no abandono de projetos como do Conselho Federal de Jornalismo, a criação de uma Agência Nacional de Cinema e do Audiovisual (ANCINAV), e da alteração da diretriz 22 do Plano Nacional de Direitos Humanos. Decepcionando ainda mais os grupos contra-hegemônicos, aprovou o Decreto 5.820/2006 optando pelo padrão japonês de TV Digital, depois de anos de lutas por um modelo brasileiro (Lima, 2010).
} 
repressão contra a mídia comunitária. As prisões e lacres saltaram de 1.950 nos últimos anos de Fernando Henrique Cardoso para 2.759 nos primeiros momentos do governo Lula (BRAZ, 2010). E ainda veio a aprovação da Lei $10.871 / 04$, que outorgou poder de polícia aos técnicos da Agência Nacional de Telecomunicações (ANATEL) (BRAZ, 2010).

Apenas em 2006, a Comissão Nacional Pró-Conferência de Comunicação (CNPC) ${ }^{14}$ emergiu como espaço de rearticulação do movimento. Em 2007, o grupo formalizou sua existência com 36 associados de caráter nacional. Entre eles, o Coletivo Intervozes ${ }^{15}$, o FNDC e a ABRAÇO como principais interlocutores ${ }^{16}$.

A principal demanda destes atores não foi uma nova lei, mas a realização de uma Conferência de Comunicação, entendida como espaço de diálogo e reconhecimento da "sociedade civil não empresarial" como interlocutor político. Para eles, era imprescindível uma consulta pública com participação dos empresários midiáticos ${ }^{17}$. O Governo respondeu em 2009 com a criação de uma Comissão Organizadora (CO) da I Conferencia Nacional de Comunicação $^{18}$ (BRITTOS e etc., 2010).

\footnotetext{
${ }^{14}$ A iniciativa surgiu em 2006, a partir dos trabalhos da Comissão de Ciência, Tecnologia, Comunicação e Informática (CTCI), na Câmara dos Deputados. 15 O Coletivo Intervozes foi criado em 2002 e tem como agenda prioritária o Direito à Comunicação (Ramos, 2007). Ele reuniu antigas lideranças da Enecos e surgiu junto com a Campanha CRIS Brasil, e vem se constituindo como um das principais vozes de incidência para o tema na contemporaneidade (Moreira, 2011). ${ }^{16}$ São constantes os relatos nas entrevistas que destacam a falta de coesão interna. FNDC e Intervozes, em variados episódios, revelaram disputas e divergências políticas em relação à condução do grupo, principalmente no que se refere à postura em relação aos empresários.

${ }^{17}$ Este foi um dos poucos pontos de consenso interno. Celso Schroder, coordenador do FNDC, afirmava que sem o acordo dos empresários, nenhum debate da Conferência teria legitimidade”. Jonas Valente, do Intervozes, reafirmou o mesmo entendimento, apesar de divergir no processo de negociação.

${ }^{18}$ As conferências são mecanismos de consulta pública criados pela Constituição para garantir maior participação popular na formulação e avaliação de políticas públicas. Elas fazem parte da tradição democrática brasileira, sendo convocadas sistematicamente em áreas como Saúde e Educação, e um dos grandes diferenciais do governo lulista foi a convocação constante de conferências nas mais variadas áreas e segmentos, inovando o debate de Cidades, Mulheres, Juventude etc. (Avritzer, 2005). No entanto, na área da Comunicação, havia uma lacuna e nunca um evento público nacional deste porte tinha sido convocado pelo governo.
} 
Em um processo de forte tensão, e em meio a uma crise interna ao movimento, Lula realizou a I Conferência Nacional de Comunicação em 2009, último ano de seu governo. No episódio, foram aprovadas 617 propostas, muitas delas referentes aos meios comunitários, mas não se estabeleceu nenhum compromisso da sucessora Dilma Roussef com o processo.

\section{Venezuela}

A Venezuela registra um histórico de política de Comunicação bastante particular. O país liderou o debate da Nova Ordem Mundial da Informação e Comunicação (NOMIC) nos anos $70^{19}$, como reflexo da postura contraditória da Democracia do Ponto Fixo ${ }^{20}$, que mundialmente reivindicava mais pluralidade midiática, e internamente restringia e eliminava as vozes antagônicas aos grandes meios.

Na eleição de Hugo Chávez, em 1998, o país seguia regulamentado pela Lei de Telecomunicações de 1940 e pelo Regulamento da Radiodifusão de 1941, que eram omissos ao serviço não comercial. Neste cenário, as experiências de Comunicação Comunitária eram quase que inexistentes. Elas nasceram paralelamente ao governo chavista, e nos anos 2000 surgiram a Associação Nacional de Meios Comunitários, Livres e Alternativos (ANMCLA), a Rede Nacional de Televisoras Comunitárias, a Associação Mundial de Rádios Comunitárias (AMARC-ALC), entre outros. Todos com posturas bastante divergentes e ação fragmentada.

A ANMCLA é considerada a principal representação no setor. A entidade se formalizou em 2002 e reúne 300 coletivos de Comunicação alternativa e é protagonista no debate da regulação do setor. O modelo da ANMCLA é apontado como o mais radical e sua principal demanda é um sistema público de Comunicação 100\% gerido pelas comunidades.

\footnotetext{
${ }^{19}$ Em disputa com as grandes potências pelo preço do Petróleo, o Presidente Rafael Caldeira (1969-1973) reuniu expertos para a construção de uma Política Nacional de Comunicação e subsidiou o debate da Nova Ordem Mundial da Informação (NOMIC) em uma clara postura de desafio à hegemonia norte-americana (Capriles, 1989).

20 Sistema bipartidário que alternou os partidos ADN e COPEI no poder entre os anos de 1958 e 1998, excluindo as vozes dissidentes desse projeto democrático limitado e restrito (Maya, 2005).
} 
No início do ano 2000, quando a entidade ainda sequer estava formalizada, seus líderes foram contrários à política de Chávez na Lei Orgânica das Telecomunicações (LOT/2000). O grupo interpretava que o marco atendia aos interesses dos grandes conglomerados comerciais, pois permitiu a privatização dos serviços de telecomunicações. Os militantes fizeram pressão para que a mesma medida reconhecesse e promovesse o serviço de radiodifusão sem finalidade de lucro, o que foi regulamentado pelo Decreto 1.521/01.

Este foi o primeiro marco normativo do continente considerado favorável ao tema de meios comunitários (PARRA, 2006; AMARC, 2009). Diferente da lei brasileira que regulava restritivamente o serviço, o Decreto da Venezuela considerava a exploração não- comercial como um direito público, o qual deveria ser assegurado pelo Estado. Mesmo assim, a ANCLA considerava o Decreto uma normativa menor e insistia na criação de uma lei específica.

Em 2002, o cenário ganhou contornos dramáticos com o golpe midiático ${ }^{21}$ e os meios comunitários foram decisivos na rede de notícias contra-hegemônicas que ajudou a restabelecer o presidente. Depois do episódio, conquistaram a Lei de Responsabilidade Social no Rádio e TV (Resorte/2004), que fomentou a produção audiovisual independente. $\mathrm{O}$ país também assinou o Convênio de Cooperação Integral Cuba-Venezuela (2004-2007) para compra de equipamentos para os meios comunitários, criou órgãos específicos ${ }^{22}$ para o setor, empossou a primeira ministra ${ }^{23}$ das

${ }^{21}$ Em 2002, os grandes meios de Comunicação estiveram diretamente envolvidos no golpe de Estado que destituiu temporariamente o presidente Hugo Chávez. A Comunicação alternativa foi fundamental no sistema de contra-informação que permitiu a reação popular e o re-estabelecimento do presidente e da ordem democrática. Esse episódio marca profundamente a história política contemporânea da Venezuela.

${ }^{22}$ Em 2004, o Ministério do Poder Popular para a Comunicação e Informação (MinCI) criou a Direção Nacional de Meios Comunitários. Também a Conatel, a agência de regulação do setor, destinou uma gerência específica para o setor. Destaca-se que a visão dos órgãos era explicitamente a de substituir o papel repressivo do Estado, e gerar políticas de fomento na área, realizando o que chamavam de "acompanhamento técnico e social".

${ }^{23}$ Blanka Eekhout assumiu o (MinCI) em 2009. Ela foi fundadora de Cátia TV, uma das televisoras comunitárias mais ativas de Caracas. 
comunicações vinculada a uma emissora comunitária, e facilitou burocraticamente as concessões (SEL, 2010).

Mas essa relação não foi tão harmônica quanto parece. $\mathrm{Na}$ época das entrevistas (2010), a ANMCLA expressava várias inconformidades com a política governamental, como a ausência de critérios claros para a distribuição de recursos públicos para as emissoras, a inexistência de espaços de co-gestão, como um conselho de Comunicação com participação dos meios comunitários, e a falta de continuidade da política estatal (MOREIRA, 2011). Eles relatam que houve uma diminuição significativa do apoio chavista, agora mais empenhado em estabelecer seus próprios meios (BISBAL, 2006). Essas insatisfações evidenciam os desafios da militância na Comunicação em uma sociedade polarizada, e a tendência do Estado em se apropriar dos meios para a função de propaganda política.

\section{Conquistas}

Analisando comparativamente o número de concessões conquistadas no período, o curioso é que o Brasil foi o país que mais reconheceu emissoras comunitárias na última década. Até o ano de 2011, no país, existiam 4.201 rádios comunitárias regularizadas. Na Argentina, eram apenas 126, e outras 270 tinham permissão na Venezuela. Mas então porque no Brasil as entrevistas revelaram o movimento com maior grau de frustração em relação a nova esquerda? Para obter a resposta, basta fazer a comparação dos avanços em relação aos governos anteriores (quadro 1).

Este olhar comparativo ajuda a entender o desânimo do movimento brasileiro porque quase não houve diferença percentual entre as conquistas e permissões nos últimos quatro anos da gestão neoliberal de FHC e as conquistas na legalização de emissoras em todos os oito anos lulistas. Na Venezuela, os protagonistas da Comunicação Comunitária associam o boom do setor com o programa chavista, apesar das divergências. E na Argentina, todas as permissões conquistadas são anteriores à aprovação da nova lei, e a ênfase deste caso é a própria alteração normativa, conforme mostra o quadro 2 . 
Quadro 1 - Percentual de comunitárias aprovadas antes e depois das novas esquerdas.

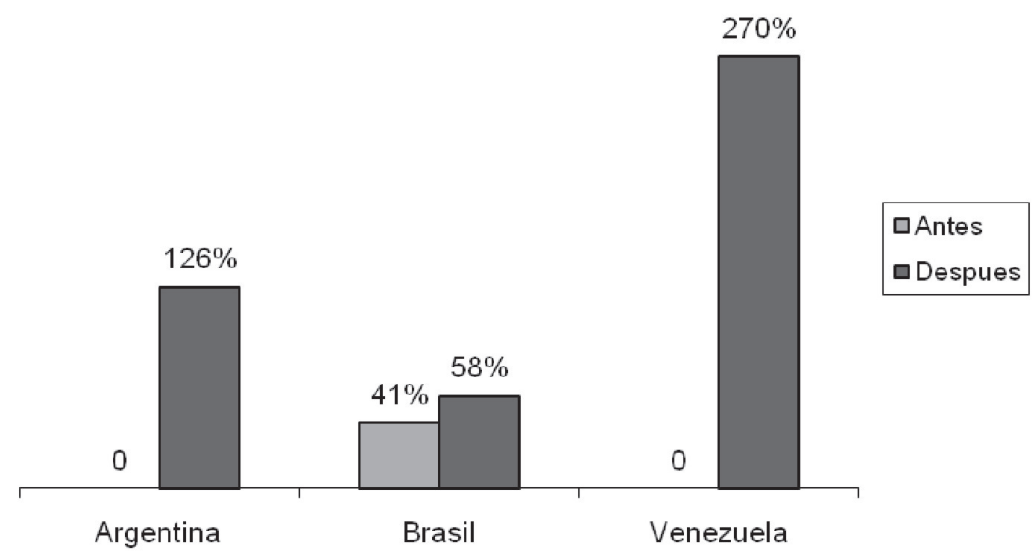

Fonte: Elaboração própria com base em dados coletados com os órgãos oficiais.

Quadro 2 - Regulação Comunicação Comunitária antes e depois das esquerdas.

\begin{tabular}{|c|c|c|c|}
\hline Norma & Argentina & Brasil & Venezuela \\
\hline Antes & $\begin{array}{l}\text { Ausência de nor- } \\
\text { mativa específica. } \\
\text { Lei } 22.285 / 80 \text { cri- } \\
\text { minaliza o serviço. }\end{array}$ & $\begin{array}{l}\text { Lei } 9.612 / 98, \text { que } \\
\text { regulamenta restrititi- } \\
\text { vamente a radiodifusão } \\
\text { comunitária. Código } \\
\text { Brasileiro de Teleco- } \\
\text { municações de } 1962 \\
\text { criminalizava o serviço. }\end{array}$ & $\begin{array}{l}\text { Ausência de nor- } \\
\text { mativa. } \\
\text { Lei de Telecomu- } \\
\text { nicações de } 1940 \\
\text { criminalizava o } \\
\text { serviço. }\end{array}$ \\
\hline Depois & $\begin{array}{l}\text { Decreto Lei } \\
\text { 26.053/05, reco- } \\
\text { nhece o serviço } \\
\text { não comercial; } \\
\text { Lei 26.522/09, } \\
\text { considerada um } \\
\text { marco pluralista } \\
\text { pelas Relatorias } \\
\text { de Liberdade de } \\
\text { Expressão da OEA } \\
\text { e Unesco. }\end{array}$ & $\begin{array}{l}\text { Debates frustrados; } \\
\text { Lei } 10.871 / 04 \text {, outorga } \\
\text { poder de polícia para } \\
\text { agentes da Anatel. }\end{array}$ & $\begin{array}{l}\text { Decreto } 1.521 / 01 \\
\text { regulamenta o ser- } \\
\text { viço de Comunica- } \\
\text { ção Comunitária; } \\
\text { Lei Resorte/2004, } \\
\text { favorável à produ- } \\
\text { ção de conteúdos } \\
\text { alternativos. }\end{array}$ \\
\hline
\end{tabular}

Fonte: Elaboração própria com base nas normativas analisadas 
A regulação dos meios comunitários avançou na Argentina e Venezuela, com medidas favoráveis às demandas do movimento. No Brasil, podemos falar de um retrocesso, com medidas que fortaleceram a repressão. Considerando que o modelo brasileiro optou pela continuidade da Lei 9612/98, aprovada no período de avanço neoliberal, se constituiu como o cenário normativo menos favorável à contra-hegemonia comunicativa. Para sustentar este argumento, é interessante comparar as regras(quadro 3).

Quadro 3 - Diferenças legais na regulação dos meios comunitários.

\begin{tabular}{|c|c|c|c|}
\hline Definições & Argentina & Brasil & Venezuela \\
\hline Concessionários & $\begin{array}{l}\text { Sociedade civil } \\
\text { sem finalidade de } \\
\text { lucro (sindicatos, } \\
\text { ongs, associações de } \\
\text { moradores, etc.) } \\
\end{array}$ & $\begin{array}{l}\text { Associações e } \\
\text { fundações de } \\
\text { radiodifusão } \\
\text { comunitária. }\end{array}$ & $\begin{array}{l}\text { Fundações } \\
\text { comunitárias. }\end{array}$ \\
\hline $\begin{array}{l}\text { Reserva legal } \\
\text { do espectro }\end{array}$ & $33.00 \%$ & Sem reserva. & Sem reserva. \\
\hline $\begin{array}{l}\text { Especificações } \\
\text { técnicas }\end{array}$ & $\begin{array}{l}\text { Sem limitações } \\
\text { geográficas e de potência. }\end{array}$ & $\begin{array}{l}1 \mathrm{~km} \text { de raio. } \\
\text { Potência máxima } \\
\text { de } 25 \text { watts e } 01 \\
\text { por município. }\end{array}$ & $\begin{array}{l}01 \text { por bairro, } \\
\text { transmissor de } \\
600 \mathrm{khz}, \text { com } \\
\text { expansão de } \\
\text { sinal sujeita } \\
\text { a análise de } \\
\text { Conatel. } \\
\end{array}$ \\
\hline Sustentabilidade & $\begin{array}{l}\text { Sem limitações e com } \\
\text { possibilidades de apoio } \\
\text { governamental. }\end{array}$ & $\begin{array}{l}\text { Proíbe a } \\
\text { publicidade } \\
\text { e não prevê } \\
\text { financiamento } \\
\text { governamental. }\end{array}$ & $\begin{array}{l}\text { Permite } \\
\text { publicidade } \\
\text { de pequenas } \\
\text { empresas } \\
\text { locais e apoio } \\
\text { governamental. }\end{array}$ \\
\hline $\begin{array}{l}\text { Prazo das } \\
\text { licenças }\end{array}$ & $\begin{array}{l}15 \text { anos e possibilidade } \\
\text { de renovação por mais } \\
10 \text { anos. }\end{array}$ & $\begin{array}{l}03 \text { anos e } \\
\text { renovação por } \\
\text { mais } 10 \text {. }\end{array}$ & Não explicita. \\
\hline $\begin{array}{l}\text { Procedimentos } \\
\text { de outorgas }\end{array}$ & Não regulamentado. & $\begin{array}{l}\text { Concurso público, } \\
\text { e processo } \\
\text { burocrático, } \\
\text { considerado lento. }\end{array}$ & $\begin{array}{l}\text { Solicitação } \\
\text { com projeto } \\
\text { de viabilidade } \\
\text { econômica. }\end{array}$ \\
\hline
\end{tabular}

Fonte: Elaboração própria com base nas normativas analisadas e nos princípios da Amarc. 
Tomando apenas como referência as especificações técnicas, faremos uma análise parcial do modelo normativo. No caso argentino, o formato da emissora é livre, o que permite inclusive rádios e televisoras comunitárias de caráter nacional. Ou seja, o que define o meio é sua finalidade social, não-comercial, e não sua limitação geográfica.

No Brasil, além da definição geográfica restrita e incoerente com as distâncias brasileiras, a normativa tem critérios curiosos, como o que obriga o diretor de uma emissora comunitária a residir há um quilômetro do transmissor, uma medida similar aos presos que gozam de liberdade condicional. Os entrevistados brasileiros classificam estas especificações como "surreais". Se cumpridas literalmente, elas tornam inviável (e ilegal) o funcionamento de qualquer emissora comunitária. Por exemplo, uma rádio que cumpre a determinação de uma antena de 30 metros e o transmissor de 25 watts, tecnicamente tem um sinal com potência superior ao limite de um quilômetro de transmissão. Muitos radialistas contam que esse é o argumento de muitos técnicos da Anatel que decretam o lacre dos equipamentos e ameaçam com prisão aos comunicadores por descumprirem a lei.

$\mathrm{Na}$ Venezuela, a concepção de comunitário também é geográfica, mas a abrangência do sinal é maior que no caso brasileiro e a normativa permite ampliações. O problema é a discrecionalidade, pois o aumento do raio de distribuição depende de parâmetros que não estão previamente determinados. Faltam especificações de procedimentos decisórios em vários aspectos da normativa, sujeitando o processo ao risco de arbitrariedades do executivo e a adoção de critérios pouco confiáveis.

A partir deste cenário, podemos avançar em um quadro comparativo que interpreta a normativa a partir de uma visão geral da política de Comunicação Comunitária implantada. Foram fixados eixos de análise construídos a partir de parâmetros internacionais do direito à Comunicação, e dos pilares básicos para o funcionamento de uma emissora, e a classificação foi estabelecida a partir da análise dos entrevistados. A ideia é gerar uma classificação das políticas de Comunicação Comunitária para além do número de frequências ou da interpretação estrita das normativas. 
Quadro 4 - Política de Comunicação Comunitária nas Novas Esquerdas.

\begin{tabular}{l|l|l|l}
\hline Política de Comunicação Comunitária & Argentina & Brasil & Venezuela \\
\hline $\begin{array}{l}\text { Base legal (normas de reconhecimento } \\
\text { do serviço) }\end{array}$ & Favorável & Restritiva & Limitada \\
\hline $\begin{array}{l}\text { Políticas públicas (arquitetura estatal } \\
\text { para gestão do tema) }\end{array}$ & Favorável & Restritiva & Favorável \\
\hline $\begin{array}{l}\text { Descriminalização (tratamento do tema } \\
\text { como direito e não como crime) }\end{array}$ & Favorável & Restritiva & Favorável \\
\hline $\begin{array}{l}\text { Financiamento (mecanismos legais, } \\
\text { modelos de apoio e disponibilidade de } \\
\text { recursos) }\end{array}$ & Favorável & Restritiva & Limitada \\
$\begin{array}{l}\text { Participação (representação do } \\
\text { movimento nas decisões políticas, } \\
\text { existência e regularidade dos espaços de } \\
\text { co-gestão) }\end{array}$ & Favorável & Limitada & Restritiva \\
\hline
\end{tabular}

Fonte: Elaboração própria

Da síntese desses contextos, podemos interpretar que a primeira década dos anos 2000 terminou com três tipos distintos de políticas de Comunicação Comunitária. Registramos na Argentina um avanço institucional, comprometido apenas pela judicialização do tema; o Brasil foi o avanço conservador, dirigido ao reconhecimento político de novos atores, mas sem mudanças estruturais; e na Venezuela, temos um avanço polarizado, que apontou conquistas aceleradas, mas sujeitas aos excessos governamentais e com poucos contrapesos institucionais.

\section{Considerações finais}

As viradas democráticas para a esquerda na América Latina foram uma oportunidade de novas práticas de regulação dos meios e abriram brechas importantes para a incidência dos movimentos sociais comunicativos. No entanto, é importante destacar que não foi identificado que nenhuma dessas "novas esquerdas" trazia em 
seus programas a defesa do pluralismo e da democratização dos meios, ou parecia planejar uma política específica para a Comunicação Comunitária.

No início, a ação desses governos foi de indiferença para o tema e evidentemente optaram por tentativas de reacomodação com os grupos hegemônicos da Comunicação. Na Argentina e na Venezuela, a conciliação entre os interesses do Estado e dos empresários não aconteceu e a ruptura com a mídia tradicional foi decisiva para aproximar estes governos da mídia comunitária. Só depois de definir sua relação com os meios hegemônicos, as gestões Kirchner e Chávez se aproximaram da agenda progressista da Comunicação. No Brasil, a opção lulista de pactuar com as elites, o levou a evitar o conflito midiático e a se esquivar do enfrentamento do debate da regulação. Não por acaso, no Brasil onde esta ruptura entre mídia e governo não aconteceu, a Comunicação Comunitária registrou o processo com menos resultados normativos.

Este cenário indica a limitação das "novas esquerdas" em pensar um modelo de Comunicação para além da dicotomia estatal (domínio político) ou privado (exploração mercantil). A falta de entendimento da política de Comunicação como um direito público e a ausência de um projeto político-comunicativo da esquerda com perspectivas progressistas, parece colocar o futuro dessas conquistas em xeque. Constatação que provoca a sensação de incertezas. Seja pelas indefinições judiciais no caso argentino, pela paralisia do executivo brasileiro, quanto pelos extremismos venezuelanos, todas essas políticas se revelam ainda frágeis, pouco consolidadas e com destino indefinido. $\mathrm{O}$ que este estudo indica é que modelos mais plurais e democráticos de políticas de Comunicação dependem da pressão organizada e continuada dos movimentos sociais comunicativos.

\section{Referências}

AGUIRRE, Jesús Marua. Democratizar la comunicación: El caso Venezuela. Aprendiendo de la adversidad. 17 Anuario Ininco - Investigaciones de la comunicación, 1, 2005. 
AMARC. Las mordazas invisibles. Asociación Mundial de Radios Comunitarias. 2009. Disponível em: http://legislaciones.amarc.org/mordazas/Libro_LasMordazasInvisibles.pdf. Acesso em: 05 jan.2011.

. Principios para garantizar la diversidad y el pluralismo en la radiodifusión y los servicios de comunicación audiovisual. Buenos Aires: AMARC, 2010.

AVRITZER, Leonardo. Las instituciones participativas em el Brasil democrático. Jalapa: Universidad Veracruzana, 2010.

BECERRA, Martín; MASTRINI, Guillermo. Los dueños de la palabra: acceso, estructura y concentración de medios en la América Latina del siglo XXI. Buenos Aires: La Crujía, 2009.

BISBAL, Marcelino. El estado-comunicador y su especificidad: diagnóstico inacabado y estrategias. Caracas, 2006.

BRAZ, Rodrigo. Estado e comunicação: uma análise dos modos de regulação da radiodifusão no Brasil e na Venezuela. Dissertação (Mestrado em Comunicação)-Universidade de Brasília, Brasília, 2010.

BRITTOS, Valério; ROCHA, B.; NAZÁRIO, P. Comunicação, Conferência e pauta de democratização. São Leopoldo: Artigo apresentado ao Grupo Cepos em 2010. Disponível em http://www.cebela.org.br/site/baCMS/ files/38521ART1\%20Valerio\%20Brittos.pdf. Acesso em: 05 jan.2011.

BOITO JR. A. A hegemonia neoliberal no governo Lula. 17, 9-35. São Paulo: Cemarx, 2010.

FOX, E. Latin American Broadcasting: from tango to telenovela. Luton, UK: John Libbey Media, 1997.

. ; WAISBORN, S. Latin politics, global media (1st ed.). Austin:

University of Texas Press, 2002.

GUMUCIO-DAGRON, A.; TUFTE, T. (Coords.). Communication for social change: antology historical and contemporary readings. New Jersey: CFSC Consortium, 2006.

MASTRINI, Guillermo.(Org.). Mucho ruido, pocas leyes: economía y políticas de comunicación en argentina 1920-2007 (2da ed.ampl.). Buenos Aires: La Crujía, 2009. 
- ; BECERRA, Martín. Los dueños de la palabra: acceso, estructura y concentración de medios en la América Latina del siglo XXI. Buenos Aires: La Crujía, 2009.

MORAES, Dênis de. A batalha da mídia: Governos progressistas e políticas de Comunicação na América Latina e outros ensaios. Rio de Janeiro: Pão e Rosa, 2009.

MOREIRA, Gislene. Las hormigas de macondo: Contrahegemonía y políticas de comunicación comunitaria en Argentina, Brasil y Venezuela. 2011. Tese (Doutorado em Ciências Políticas) - Flacso, México.

NATANSON, José. La nueva izquierda: Triunfos y derrotas de los gobiernos de Argentina, Brasil, Bolivia, Venezuela, Chile, Uruguay y Ecuador. Buenos Aires, Sudamericana, 2009.

PARRA, Luz Neira. Hacía la instalación de una nueva política comunicacional del Estado venezolano. Razón y Palabra, 2006.

PERUZZO, Cicília M.K. Rádios comunitárias no Brasil: da desobediência civil e particularidades às propostas aprovadas na CONFECOM. Rio de Janeiro: Compós, 2010.

PLOT, Martín ; SEMÁN, Ernest. Mapping Latin America's response to neoliberalism y neoconservatism. Constellations Rewiew, London, v 14, n. 3, p. 355-372. Septiembre de 2007.

RAMOS, M. Sobre a importância de repensar e renovar a idéia de sociedade civil, em Ramos e Santos. Políticas de comunicação: buscas teóricas e práticas. São Paulo: Paulus, 2007.

ROLIM, R. Rádio, movimentos sociais e direito à comunicação. Recife: Oito de Março, 2008.

Sel, Susan. (org). Políticas de comunicación en el capitalismo contemporáneo - América Latina y sus encrucijadas. Buenos Aires: Clacso, 2010.

URBINA, Jesús. Nuevos rasgos del derecho a la información en Venezuela. Caracas: Editorial Venezuelana, 2006.

Recebido em: 14/11/2012

Aceito: 04/04/2013 